\title{
REVISIÓN
}

\section{TRANSPORTADORES CELULARES DE DROGAS. EL VIAJE DE LOS ANTIDIABÉTICOS ORALES POR EL ORGANISMO}

\author{
CELLULAR DRUGS TRANSPORTERS. THE JOURNEY OF \\ THE ORAL ANTIDIABETICS AGENTS TROUGH THE ORGANISM
}

Héctor Alejandro Serra', Cristian Suárez Cordo ${ }^{1}$, Jorge Alvariñas ${ }^{1}$, Julio César Bragagnoloํ, Gustavo Frechtel ${ }^{1}$, Pilar Cean', Claudia Folino', Analía Dagum', Susana Salzberg'

\section{RESUMEN}

La diabetes mellitus tipo 2 requiere tratamiento farmacológico múltiple para lograr los objetivos establecidos y el control de las comorbilidades. Por lo tanto, dicho tratamiento propende a la interacción medicamentosa. Se entiende por tal a los efectos observados, sean terapéuticos o adversos, resultantes de la administración concomitante de dos o más fármacos a un paciente, concepto que debería extenderse a los alimentos, cosméticos y sustancias ambientales.

Durante años las interacciones entre drogas se estudiaron en forma descriptivo-empírica y recién en las últimas décadas se dio jerarquía a los mecanismos participantes. Las interacciones farmacocinéticas involucran los procesos absortivos, distributivos y de eliminación donde intervienen enzimas y moléculas de transporte, y en la actualidad se aprecia un interés aún mayor por estas últimas como fuente de interacciones.

El objetivo de este trabajo es describir los transportadores intervinientes en la farmacocinética de los antidiabéticos orales $y$, de esta manera, discernir si potencialmente pudiera existir alguna interferencia al momento de indicar un nuevo fármaco agregado.

Palabras clave: transporte celular de drogas, farmacocinética, antidiabéticos orales.

Revista de la Sociedad Argentina de Diabetes 2017; Vol. 51 (137-152)

\begin{abstract}
Type 2 diabetes mellitus requires multiple pharmacological treatment in order to achieve therapeutic goals and control comorbidities. Therefore, treatment leads to drug interaction. It means that the observed effects, whether therapeutic or adverse, are the result of the concomitant administration of two or more drugs given to a patient. This concept should be extended to foods, cosmetics and environmental substances. For many years, drug interactions were studied in a descriptive-empirical way, but in the last decades the participating mechanisms were hierarchized.

Pharmacokinetic interactions involve absorptive, distributive and elimination processes in which enzymes and transport molecules are involved. Nowadays there is an even greater interest in the latter as a source of interactions.

The purpose of this paper is to describe the transporters involved in the pharmacokinetics of oral antidiabetic agents, and in this way to realize if there could potentially be any interference when another drug is added.
\end{abstract}

Key words: cellular drug transport, pharmacokinetics, oral antidiabetics agents.

Revista de la Sociedad Argentina de Diabetes 2017; Vol. 51 (137-152)

${ }^{1}$ Comité de Farmacología de la Sociedad Argentina de Diabetes

Contacto del autor: Cristian Suárez Cordo

E-mail: csuarezcordo@gmail.com

Correspondencia: Paraguay 1307, piso $8^{\circ}$ ofic. 74 (C1057AAU), CABA, Argentina

Fecha de trabajo recibido: 05/11/17

Fecha de trabajo aceptado: 21/11/17

Tel.: (011) 11-5938-9511

\section{Conflictos de interés:}

Héctor Alejandro Serra: asesor médico en Química Montpellier.

Cristián Suárez Cordo: participación en disertaciones para Eli Lilly y Boehringer Ingelheim.

Jorge Alvariñas: recibió honorarios por conferencias, asesoramiento, consultoría, cursos de los laboratorios Sanofi, AstraZeneca, Merck, Novo Nordisk, Craveri, Roche.

Julio César Bragagnolo: recibió en los últimos tres años honorarios de consultoría, disertación o entrenamiento de disertantes o apoyo por asistencia a congresos o equipamiento institucional por AstraZeneca, Denver Farma, Investi Farma, Janssen, Montpellier, Novartis, Novo Nordisk, Roche y Sanofi.

Gustavo Frechtel: recibió honorarios por conferencias, consultoría, investigación, asesoramiento a Sanofi Aventis, Eli Lilly, Merck, Novo Nordisk, AstraZeneca.

Pilar Cean: recibió honorarios de AstraZeneca y actualmente de Boehringer Ingelheim.

Claudia Folino: asesoró a Boehringer Ingelheim, Gador y Genzyme.

Analía Dagum: sin conflictos de interés.

Susana Salzberg: participación en disertaciones para Pfizer, AstraZeneca, Novo Nordisk; investigación: Eli Lilly, Sanofi, Merck. 


\section{ABREVIATURAS}

ABC: ATP binding cassette (cassette de unión al ATP).

BCRP: breast cancer resistant protein (proteína de resistencia del cáncer de mama).

BSEP: bile salt export pump (bomba extrusora de sales biliares).

MATE: multidrug and toxic-compound extrusion (proteína extrusora de múltiples drogas y toxinas).

MRP2: multidrug resistance protein 2 (proteína 2 de resistencia múltiple a drogas).

NBD: nucleotide binding domain (dominio de unión a nucleótidos). NTCP: Na-taurocholate cotransporting polipeptide (polipéptido cotransportador de sodio y taurocolato).
OATP: organic anion transporting polipeptide (polipéptido transportador de aniones orgánicos).

OCT: organic cation transporter (transportador de cationes orgánicos).

P-gp, MDR1: P glycoprotein (glicoproteína P), multidrug resistance protein 1 (proteína de resistencia múltiple a drogas 1).

PEPT1 y 2: peptide transporter 1 y 2 (transportador de péptidos 1 y 2).

PMAT: plasma-membrane monoamine transporter (transportador de monoaminas de la membrana plasmática).

SLC: solute carrier (portador de solutos).

SUR: sulphonylurea receptor (receptor a las sulfonilureas).

\section{INTRODUCCIÓN}

La diabetes mellitus tipo 2 (DM2) es una enfermedad compleja que compromete prácticamente a todos los órganos y sistemas del organismo, y gracias al vínculo con la obesidad y el síndrome metabólico, se ha convertido en una pandemia. Si bien los cambios en los hábitos de vida son el eje central en el tratamiento, varias veces no son suficientes. Además la falta de adherencia a los regímenes higiénicos dietéticos hacen que, en la mayoría de los casos, se requiera la participación de varios fármacos para el alcance de los objetivos ${ }^{1,2}$.

En la actualidad los fármacos juegan un rol primordial en el tratamiento de las distintas enfermedades. La prescripción farmacológica representa casi el $80 \%$ de la prescripción terapéutica que concluye la consulta médica ${ }^{3}$. El uso de varios fármacos concomitantemente en la diabetes constituye una herramienta fundamental para satisfacer, aunque sea en parte, el logro de los objetivos propuestos.

Los fármacos son agentes químicos que interactúan con la materia viva; este contacto es particular y característico. Para ejercer sus efectos necesitan circular pasando a través de las membranas biológicas que dividen los distintos compartimientos corporales, células de diversos órganos y tejidos. Este "viaje" conduce los fármacos a su sitio de acción o biofase, incluso a los órganos donde se procederá a su eliminación.

Las membranas biológicas son hidrofóbicas o impermeables al agua, mientras que la mayoría de los solutos de importancia biológica (sean iones, alimentos, vitaminas o sustancias ambientales) es más bien hidrofílico y de peso molecular mayor a 50. Por ello, estos solutos requieren la participación de proteínas específicas que los transportan para atravesarlas, ya que la difusión simple es válida sólo para aquellas moléculas de muy bajo peso molecular y electroneutras como el amoníaco, el oxígeno, el monóxido y dióxido de carbono o el óxido nítrico.

Las proteínas integrales de membrana relacionadas con el transporte de sustancias se hallan presentes en todos los organismos vivos sin importar su reino de pertenencia y son verdaderas puertas compartimentales dado que se ubican en todas las membranas biológicas incluyendo las de las organelas. Estas moléculas se dividen en cuatro grandes grupos: las acuaporinas, los canales iónicos, las ATPasas iónicas y los transportadores, siendo los tres últimos responsables del movimiento de los solutos.

Las acuaporinas son tetrámeros integrales encargados del transporte pasivo de agua entre los distintos compartimientos intracelulares; exhiben una forma de reloj de arena y contienen un poro central abierto por donde continuamente pasa agua en función del gradiente osmótico ${ }^{4}$. Los canales iónicos son oligómeros que cierran un poro central hidrofílico aislado del entorno hidrofóbico transmembranar por donde se moverán los iones específicos a favor de su gradiente electroquími$\mathrm{CO}^{5}$. Pequeños cambios conformacionales determinados por variaciones del voltaje o por ligandos (hormonas, neurotransmisores o fármacos) permiten que el canal se abra o se cierre produciendo cambios inmediatos en los potenciales de membrana y en la señalización intracelular. Su actividad se complementa con las ATPasas iónicas capaces de convertir la energía provista por la hidrólisis de ATP en gradientes iónicos (ATPasas tipo P o bom- 
bas iónicas), y viceversa, usar un gradiente impulsor para la síntesis de ATP, acidificar organelas o funcionar como verdaderos motores celulares (ATPasas F/N) ${ }^{6,7}$.

Los transportadores son también oligómeros de composición muy heterogénea. Sin ellos la vida sería incompatible porque facilitan el paso de moléculas de sumo interés metabólico como los nutrientes y permiten descartar endo y xenobióticos tóxicos ${ }^{6,8}$. Los fármacos, que son remedos de los sustratos mencionados, usan estas proteínas. Según sea su requerimiento energético, estos transportadores pueden ser pasivos o activos. Los pasivos se relacionan con la translocación bidireccional del sustrato a favor de su gradiente de concentración compartimental (difusión facilitada) y lo aprovechan para transportar iones, metabolitos y unidades estructurales de macromoléculas. Los activos gastan gradientes iónicos (sea de $\mathrm{Na}+\mathrm{O}$ de $\mathrm{H}+$ en el llamado transporte activo secundario o cotransporte) o ATP directamente (en el llamado transporte activo primario) para conducir los sustratos a través de la membrana en contra de su gradiente. Los transportadores trabajan a un ritmo más lento (resultado de los cambios conformacionales a lo largo del ciclo de transporte más el consumo energético en el caso activo) y sufren saturación (debido a la capacidad finita de sus cámaras funcionales), inhibición (fundamentalmente por competencia entre sustratos) o inducción genética controlada por receptores nucleares (que reconocen ciertos sustratos como ligandos regulatorios). De acuerdo a la información disponible, el genoma humano contiene dos superfamilias de transportadores transmembranares que emplean las drogas para su disposición y en algunos casos para su farmacodinámica: la superfamilia de proteínas transportadoras de solutos SLC (solute carrier) y la superfamilia de glicoproteínas $A B C^{6-8}$. La primera más heterogénea en cuanto a la estructura y variedad de sus miembros pero abocada pura y exclusivamente al movimiento de solutos, y la segunda más homogénea pero con funciones muy amplias que exceden el transporte de moléculas.

La mayoría de los estudios sobre interacciones farmacocinéticas se ha centrado en las vías metabólicas que sufren las drogas, especialmente las catalizadas por citocromos P450 o CYPs y la conjugación con glucuronato debido principalmente a la gran cantidad de drogas sustrato disponibles y a los polimorfismos genéticos que presentan dichas enzimas ${ }^{9}$. Sin embargo, hoy en día existe suficiente evidencia que involucra también a los sistemas de transporte de drogas en dichas interacciones pues, al igual que con las enzimas metabólicas, los transportes exhiben polimorfismos, diferentes fármacos pueden competir en su unión a un determinado sistema y estas proteínas pueden ser inhibidas o inducidas por xenobióticos diversos. Hechos que, en última instancia, culminan con cambios inesperados en las concentraciones séricas y tisulares de fármacos y desencadenan efectos tóxicos o reducen su eficacia terapéutica. De este modo, estas proteínas cobraron una importancia crucial tanto a nivel académico como a nivel de las agencias regulatorias y de la industria farmacéutica ${ }^{10}$.

El objetivo de este trabajo es revisar los mecanismos de transporte, SLC y glicoproteínas ABC que utilizan las drogas antidiabéticas orales en su farmacocinética con el fin de evaluar posibles interacciones y optimizar la terapéutica farmacológica de las personas con DM2.

\section{Superfamilias de transportadores}

\subsection{SLC}

La superfamilia más abundante de transportadores es la SLC; sus casi 400 miembros se agrupan en 52 familias $^{6}$. Se trata de proteínas globulares de más de 350 aminoácidos que pueden oligomerizarse según su necesidad funcional. Cada monómero contiene asimismo un número muy variable de hélices transmembranares (TM). A pesar de tener un 20-40\% de homología en su secuencia aminoacídica, la disimilitud estructural encontrada probablemente refleje varios orígenes evolutivos ${ }^{11}$. Los SLC transportan solutos de variada composición y estructura, desde metales e iones inorgánicos a sales biliares, nutrientes y neurotransmisores, y emplean mecanismos pasivos facilitados o activos secundarios acoplados a gradientes (sean iónicos, generados por ATPasas $\mathrm{P}$, o de sustratos orgánicos para su intercambio). A pesar de exhibir estructuras diferentes pueden transportar sustratos similares o, al revés, con la misma estructura y familia pueden no compartir la especificidad o la estequiometría de sustratos, ni los mecanismos de aprovechamiento energético. Si el sustrato a transportar es único se emplea el término uniporte, pero si hay dos o más, se lo designa como cotransporte. En este último caso, según cómo se muevan los sustratos, serán 
simportes (si se mueven en el mismo sentido) o antiportes (si lo hacen en forma opuesta). Una mayor información sobre todos los transportes SLC y sus sustratos puede encontrarse en el sitio web: www.bioparadigms.org/SLC/intro.htm.

A partir de la estructura de transportes bacterianos pueden deducirse tres arreglos estructurales y/o funcionales diferentes para los SLC huma$\operatorname{nos}^{12,13}$ (Figura 1):

- El arreglo MFS (semejante a la superfamilia de facilitadores principales bacterianos) se caracteriza por un núcleo funcional de 12 TM agrupados en dos lóbulos iguales pero invertidos de 6 TM cada uno, con o sin TM adicionales. Estos transportadores funcionan como un balancín o "sube y baja"; en reposo presentan una apertura única hacia una de las caras membranares y una cavidad que van ocupando los sustratos, en cuanto la cavidad se completa el transportador sufre un cambio conformacional que desliza la apertura hacia la otra cara cerrándose la primera. El arreglo MFS es el predominante dentro de los SLC; se ve en los transportes de difusión facilitada de glucosa (GLUT) de la familia 2, en los cotransportadores de protones y oligopéptidos de la familia 15, en los transportadores de aniones y cationes orgánicos (OAT y OCT) de la familia 22, y en los transportadores de aminoácidos de la familia 43, entre otros.

- El arreglo LeuT (semejante al transportador de leucina) presenta un núcleo funcional de $10 \mathrm{TM}$ con o sin TM extras para interactuar con otros componentes de la membrana. El núcleo agrupa los TM en dos zonas asimétricas: una plataforma con 6 TM y un ramillete o dominio de transporte con 4 TM y 2 horquillas "compuerta" hacia cada lado membranar. Estos transportes funcionan como exclusas de navegación; las horquillas, una abierta y otra cerrada, limitan una cavidad que al llenarse provoca el cierre de la primera y la apertura de la segunda hacia el lado opuesto. El arreglo LeuT es adoptado por los cotransportes de $\mathrm{Na}+/$ glucosa (SGLT1 y 2) o $\mathrm{Na}$ +/iodo (NIS) de la familia 5, por las bombas de recaptación de neurotransmisores dependientes de $\mathrm{Na}+/ \mathrm{Cl}$ - (GAT, SERT, DAT y NET) de la familia 6, por los transportes de aminoácidos heteroméricos (HAT) de la familia 7 y los cotransportes de di y tricarboxilatos de la familia 13.

- El arreglo GltPh (homólogo al transportador de glutamato) se caracteriza por 8 TM que hacen de dominio de soporte e interacción y 2 TM con 2 horquillas "puerta" que se desempeñan como dominio funcional. Los transportadores funcionan como un ascensor unidireccional que permiten la incorporación de sustratos a la célula; como en el modelo anterior existe una cavidad limitada por horquillas, pero el llenado no sólo las abre o las cierra, sino que desplaza todo el dominio funcional unos $150 \mathrm{~nm}$ hacia el interior celular. Este arreglo se aprecia en la familia 1 de cotransportes de Na+/aminoácidos entre los que se encuentran las proteínas de recaptación neuronal/glial de glutamato (EAAT).

Como se mencionó, algunos SLC forman oligómeros funcionales; los reconocidos se dan en la familia 1 donde los EAAT aparecen como homotrímeros con cada subunidad funcionante ${ }^{14}$, en la familia 7 donde algunos miembros forman heterodímeros con la familia 3 (los HAT son las subunidades activas SLC7 de 12 TM mientras que los SLC3 son cadenas grandes a predominio extracelular de solo $1 \mathrm{TM}$ muy glicosiladas, unidas por puentes disulfuro a los SLC7 y cuya función es, aparentemente, guiar a los SLC7 hacia la membrana plasmática) ${ }^{15,16}$, en la familia 13 que forman homodímeros con cada subunidad funcionante, y en la familia 51 de transportadores de esteroles y sales biliares donde sus dos miembros, SLC51A1 y A1BP o proteínas grande y auxiliar, se heterodimerizan para dar la estructura final activa. 


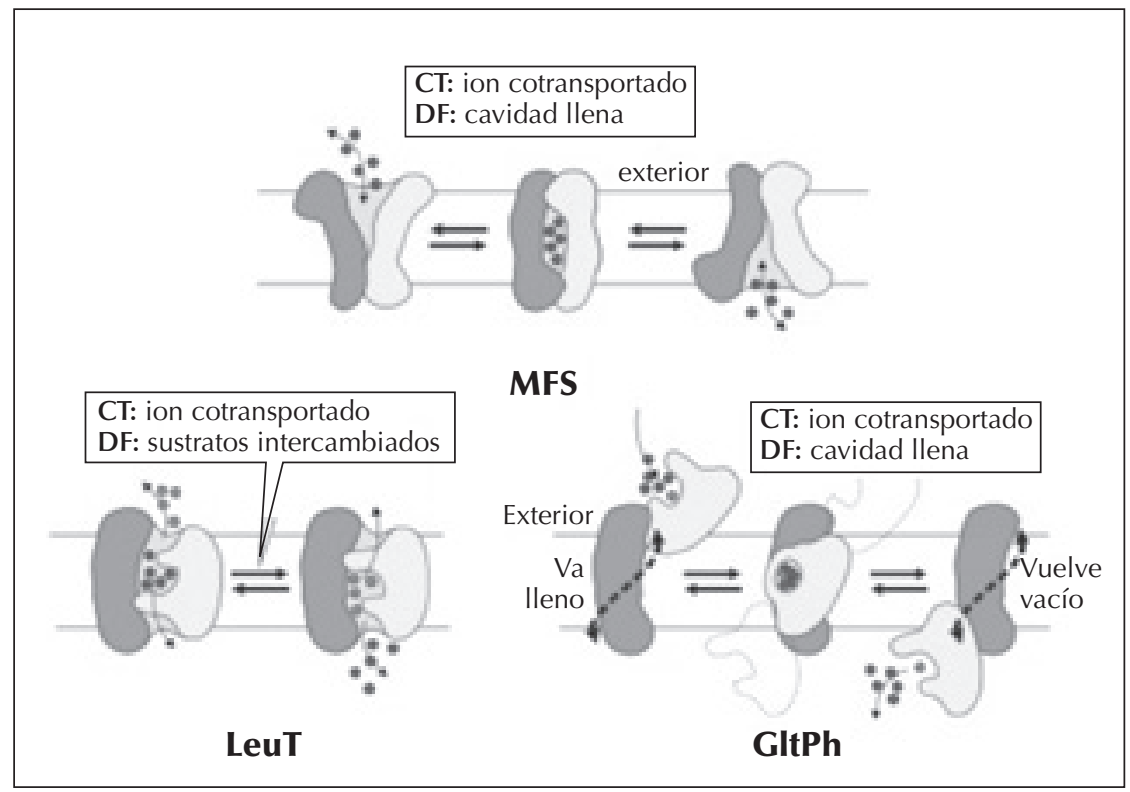

Los dibujos demuestran la forma en que funcionan las tres configuraciones descriptas de estos transportadores para mover solutos (sustratos) a través de las membranas biológicas: MFS como un balancín bidireccional que opera sobre una cavidad central llena; LeuT como una exclusa con compuertas operadas por los cosustratos o el lleno de la cavidad; GItPh como un ascensor unidireccional hacia el interior que sólo funciona tras el llenado de la cavidad de transporte (para más detalles ver el texto).

Figura 1: Estructura y función de los transportadores SLC.

\subsection{Glicoproteínas $A B C$}

Las glicoproteínas ABC eucariotas constituyen bombas de extrusión que utilizan directamente ATP como fuente de energía; se ubican preponderantemente en la membrana plasmática o en la de algunas organelas como peroxisomas, lisosomas y mitocondrias ${ }^{6,17}$. La denominación $\mathrm{ABC}$ se debe a la presencia de dominios característicos intracelulares que unen nucleótidos (NBD) designados como cassette de unión al ATP (ATP binding cassette); sin embargo, estos cassettes se hallan también en otras proteínas con función diferente como las enzimas adenilato y guanilato ciclasas o la proteína reguladora de la conductancia transmembranar de la fibrosis quística (CFTR) ${ }^{18,19}$.

En el ser humano las glicoproteínas $A B C$ representan una superfamilia de 46 miembros agrupados en siete familias (ABCA a $A B C G)^{6,7,20}$; son proteínas altamente glicosiladas con más de 1.000 aminoácidos y un arreglo común, un dominio de expansión membranar con 6 a 10 TM y un dominio NBD. Este arreglo puede ser único (medio-transportador) o repetirse (transportador completo); como la forma activa de estas proteínas es el transportador completo (expansión-NBD-expansión-NBD), los medio-transportadores deben homo o heterodimerizarse para ser funcionales ${ }^{7,17}$.

En lo que respecta al transporte, estas glicoproteínas $\mathrm{ABC}$ promueven (salvo excepciones) la expulsión citosólico-membranar de una amplia gama de compuestos como catabolitos intracelulares libres o conjugados (bilirrubina por miembros $A B C C$ ), lípidos complejos (colesterol, ceramidas, ésteres de retinol por miembros $A B C A$ y $A B C G$ ), sales biliares (mediante la ABCB11 o BSEP), péptidos (incluidos los antígenos a procesar mediante miembros $A B C B$ ), moléculas de señalización (leucotrienos y prostaglandinas por algunas $A B C C$ ), drogas y xenobióticos (mediante los miembros ABCB1 ó P-gp y ABCC1 y 2 ó MRP1 y 2), los que por sus características anfipáticas y tamaño no podrían pasar los entornos membranares. Así se hallan involucradas en una amplia variedad de procesos como la detoxificación celular, la digestión/ absorción de lípidos, la homeostasis del colesterol (en lo que respecta a la formación de HDL), la comunicación intercelular y la disposición de drogas y metabolitos. Sin embargo algunos miembros como los receptores a las sufonilureas -SUR(ABCC8 y 9) o las familias ABCE y F participan directamente en la regulación de procesos celulares finos sin promover el transporte: las primeras, al 
asociarse a los canales de K+ Kir en forma octamérica, regulan la potencial de reposo celular, y las segundas modulan la síntesis de proteínas de exportación al unirse a los factores de elongación en las inmediaciones del retículo endoplásmico ${ }^{6}$.

Los transportes $A B C$ funcionan como un balancín (símil los arreglos NFS de los SLC) aunque unidireccional. Los 12-20 TM del transportador completo forman una amplia cavidad abierta hacia el interior que acepta un amplio espectro de sustratos (aunque residuos específicos determinan cierta selectividad de compuestos según tipo, acidez, tamaño o conjugación) provenientes del citosol o de la membrana adyacente. Una vez llena, y previa hidrólisis de ATP fijado al NBD, se produce un cambio conformacional donde el poro interno se cierra y el externo se abre provocando la expulsión del contenido cavitario al exterior,17 (Figura 2).

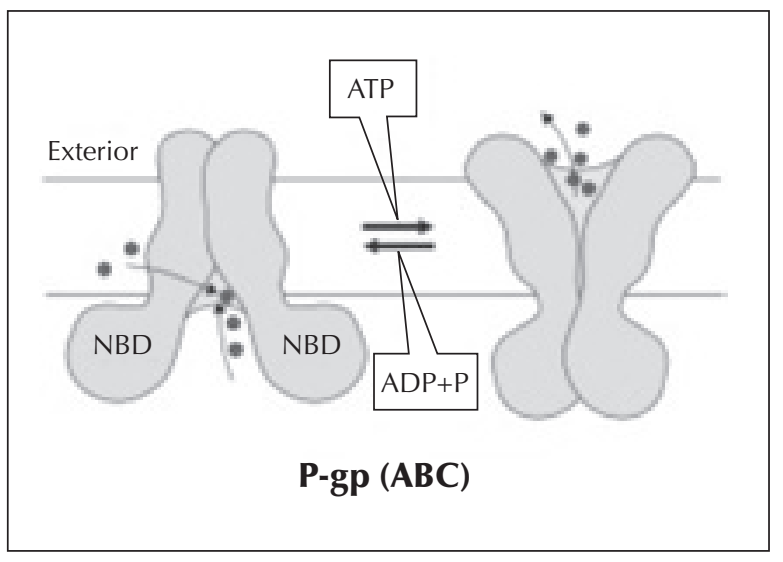

La estructura y función de las glicoproteínas ABC está ejemplificada en este caso por la P-gp. También trabaja como balancín unidireccional cuya cavidad recibe sustratos grandes anfifílicos desde el citosol o desde la membrana que la contiene. El ATP opera la proteína porque acerca los dominios de unión al nucleótido (NBD) intracelulares y ello abre la cavidad hacia el exterior (para más detalles ver el texto).

Figura 2: Estructura y función de las glicoproteínas $A B C$, ejemplificada en este caso por la P-gp.

\section{Transportadores y farmacocinética de los antidiabéticos orales}

La farmacocinética estudia los procesos que determinan el movimiento de los fármacos por el organismo desde su entrada (absorción o aplicación intravenosa) hasta su salida (eliminación por excreción), pasando por la distribución (para alcanzar la biofase y los órganos de eliminación por metabolismo $)^{21}$.
Como el organismo es un compartimiento acuoso separado por membranas biológicas impermeables al agua e iones, los fármacos, que se precian de tener un tamaño y un peso molecular aceptables a la vez que presentan cargas modificables por el pH, cuando deben moverse por el organismo lo hacen usando los transportadores (Figura 3). Por lo tanto, la farmacocinética de una molécula dada se halla condicionada por la presencia y funcionamiento de estas proteínas en una ubicación dada. Esto resulta de una expresión genética adecuada de variantes polimórficas funcionales de los transportadores, de la presencia de los cofactores necesarios para que funcione, de que el sustrato a movilizar se halle en concentración no saturante, y de la presencia o falta de otros sustratos que, al modificar el transporte, provoquen interacciones de importancia. De esto se deprende la necesidad de ser cauto al momento de prescribir e indicar a los pacientes la dosis y el horario apropiados para evitar interferencias entre drogas y de éstas con los alimentos ${ }^{3}$.

A modo de referencia, las Tablas 1 y 2 muestran los miembros de ambas superfamilias involucradas en el transporte de drogas por el organismo. De ellas se desprende que los OATP1A2, 1B1 y $1 \mathrm{~B} 3$ son los principales transportes absortivos de drogas, mientras que los MATE1 y 2 y todas glicoproteínas señaladas (P-gp, MRPs y BCRP) son los principales sistemas moleculares de excreción. A continuación, se realiza una breve descripción de las principales características farmacocinéticas de cada grupo de antidiabéticos orales y qué transportadores se hallan involucrados en la misma con el objetivo de explicar alguno de sus comportamientos comentados. Finalmente la Tabla 3 aplica los datos bajo análisis para destacar qué potenciales interacciones medicamentosas pueden tener los mismos a nivel de estos transportes que tan importantes resultan para la fisiología celular.

\section{Metformina}

En nuestro medio como en otras partes del mundo la metformina es considerada primera línea de tratamiento de la $\mathrm{DM}^{22}$. Por su grupo gunidinio es una molécula catiónica cargada positivamente a cualquier $\mathrm{pH}$, lo cual establece una hidrosolubilidad marcada que condiciona su farmacocinética. En el hombre la droga casi no se une a las proteínas plasmáticas, no se metaboliza ni se excreta por bilis, no atraviesa la barrera hematoencefálica, su volumen 
aparente de distribución queda limitado al agua extracelular y se excreta casi exclusivamente por vía renal ${ }^{23}$. Asimismo se ha demostrado que es mucho más efectiva por vía oral que por vía intravenosa, producto de su principal sitio de acción, el eje enterohepático ${ }^{24}$. Para esta cinética-dinámica particular utiliza varios de los transportadores SLC (PMAT y OCTs para su absorción y acción intestinal, OCT1 para su actividad sobre el hígado, OCTs y MATEs para su eliminación renal) ${ }^{25}$, pero no la P-gp ${ }^{26}$.

Varios rasgos interesantes y poco comprendidos de la metformina son su absorción y su interacción con los contrastes iodados que no se condicen con las características descriptas de los transportadores mencionados.

La absorción oral es saturable con dosis superiores a $1,5 \mathrm{~g}$ por vez y en el mejor de los casos la biodisponibilidad oral alcanza el $55 \%{ }^{23}$. La saturación es un rasgo de los transportadores, pero PMAT casi no se expresa en el intestino humano y los OCTs son de ubicación basolateral preponderante, es decir hay pocos apuntando a la luz del órgano. Asimismo variantes alélicas hipofuncionantes del gen del OCT1 humano (SLC22A1) ${ }^{27}$ provocan en sus portadores -ante dosis usuales de metformina y en comparación con individuos portadores del gen normal- cambios significativos en la farmacocinética (mayores niveles plasmáticos y mayor área bajo la curva con menor clearance total sin retardo en el tiempo al pico máximo), hechos que son compatibles con un transportador involucrado en la distribución-excreción más que en la absorción. Entonces, ¿cómo se absorbe la metformina? Podría postularse que usa la vía paracelular ${ }^{28}$ para alcanzar el agua extracelular y desde allí se distribuya por el organismo usando principalmente OCT1. Justamente los animales knock out OCT1 carecen de capacidad de respuesta a la droga, avalando el papel de ese transporte en la distribución-dinámica de la metformina ${ }^{27}$ pero no en la absorción, aunque por el contrario un estudio demostró que la intolerancia digestiva a la metformina era cuatro veces mayor en individuos con polimorfismos hipofuncionantes del OCT1 que además recibían simultáneamente drogas inhibidoras de ese transportador ${ }^{29}$, hechos que sugieren una reducción de la captación intestinal mediada por OCT1 (siempre y cuando se especule que los efectos adversos gastrointestinales se deben a una mayor concentración luminal de metformina ${ }^{30}$ y no al exceso de glucosa no absorbida por acción de la misma).
La metformina sufre filtración glomerular con un poco de reabsorción proximal (por la presencia apical de OCT1), pero se excreta activamente a nivel tubular (proximal y distal) usando la dupla acoplada OCT2 basolateral y MATE1 y 2-K apicales, siendo ésta el mecanismo principal de eliminación ${ }^{23,25}$. El menor clearance de la droga por hipofunción renal o interacciones a este nivel puede precipitar intoxicación con predisposición a la acidosis lácti$\mathrm{ca}^{31}$. Diversas drogas catiónicas (antidepresivos tricíclicos, antagonistas alfa adrenérgicos, diuréticos ahorradores de $\mathrm{K}_{+}$, trimetoprima, inhibidores de la bomba de protones, antihistamínicos varios, bloqueantes cálcicos) usadas en forma concomitante con metformina pueden inhibir los OCTs renales y provocar los mismos cambios farmacocinéticos que los alelos hipofuncionantes del SLC22A $1^{32}$ y favorecer la acidosis. Sin embargo, la recomendación de la Administración Federal de Drogas y Alimentos (FDA, su sigla en inglés) de Estados Unidos -que sostiene la necesidad de suspender la metformina ante la realización de un estudio con sustancias de contraste iodadas para evitar la acidosis láctica (tal como figura en los prospectos ${ }^{31,33}$ )- ha generado controversias pues una serie de evidencias, acumuladas durante casi dos décadas por las sociedades científicas involucradas, sugiere que esta recomendación se aplique únicamente a los pacientes con lesión o hipofunción renal previa y no a los diabéticos en general ${ }^{34}$.

\section{Sulfonilureas}

A diferencia de la metformina, estas drogas son anfóteras con cierto grado de liposolubilidad que permiten una absorción oral óptima con muy buena biodisponibilidad (95-100\%); asimismo tienen alta unión a proteínas plasmáticas (88-99\%), atraviesan la barrera placentaria y pasan a la leche materna. La clorpropamida es la única de eliminación renal predominante mientras que las de segunda generación (glibenclamida, glimepirida, gliclazida, glipizida) se metabolizan en el hígado vía CYP2C9 y 2C19; algunas, como glibenclamida y glimepirida, producen metabolitos activos. La eliminación de los metabolitos conjugados se efectúa por vía renal y parte de los activos se excretan también por vía biliar ${ }^{35,36}$.

Existen evidencias que la glibenclamida y la glimepirida son sustratos OATPs, P-gp, MRP3 y $B C R P^{37,38}$, datos que pueden fácilmente extrapolarse a los otros miembros de esta familia. A 
partir de éstos puede esbozarse que la absorción intestinal de las sulfonilureas se lleva a cabo por los OATP1A2 y 2B1, acción que no se ve entorpecida por la extracción P-gp mediada (lo que se ve reflejada en la elevada biodisponibilidad) como se observa con otras drogas ya que las sulfonilureas la inhiben ${ }^{39}$. Asimismo la entrada hepática mediada por los OATP1Bs es lenta y por ello, no se ve el efecto del primer paso (lo que da como resultado la excelente biodisponibilidad). La excreción de sulfonilureas de segunda generación a la leche materna y de sus metabolitos conjugados (polo biliar o túbulo proximal) son resorte de la BCRP y de algunos miembros MRP, y lo mismo puede decirse para la secreción tubular de clorpropamida. Finalmente, la inhibición de la P-gp y BCRP reduce la capacidad de retrotransporte placentario y facilita el pasaje de estos fármacos a la circulación fetal ${ }^{38,40}$. Sin embargo todos estos hechos no parecerían ser de gran relevancia para las interacciones de las sulfonilureas dado que hay poca información al respecto ${ }^{37,41}$.

\section{Metiglinidas}

Las metiglinidas son rápidamente absorbidas por vía oral con una biodisponibilidad que no supera el $70 \%$. Tienen alta ligadura proteica (98\%), un volumen de distribución escaso y rápida metabolización-excreción de metabolitos. La repaglinida se metaboliza mediante el CYP3A4 y los metabolitos se excretan por bilis, mientras que la nateglinida lo hace por los CYP2C9 y 3A4 se excreta por riñón un $20 \%$ inmodificada ${ }^{42}$. En su farmacocinética las metiglinidas utilizan los OATP1Bs para la absorcióncaptación hepática/metabolismo y el OCT1 para la distribución y probablemente para la excreción ${ }^{36,37}$, pero no hay referencias si los metabolitos usan la BCRP o los MATEs para su excreción.

\section{Tiazolidindionas o glitazonas}

Las tiazolidindionas, pioglitazona y rosiglitazona son lo suficientemente anfifílicas como para absorberse bien $y$, de hecho, presentan una alta biodisponibilidad (80-100\%). Tienen amplia distribución con alta ligadura proteica (99\%), sin embargo pasan poco al tejido nervioso. Suelen usarse en asociación con metformina para una mejor actividad terapéutica. Hay mucha evidencia sobre la farmacogenómica e interacciones relacionadas con su metabolismo en manos de los CYP2C8, $2 \mathrm{C} 9$ y $3 \mathrm{~A} 4^{36,43,44}$ pero poco y nada sobre su transporte por el organismo. Se ha descripto que las glitazonas son sustrato OATP1Bs, P-gp y BCRP ${ }^{37}$. Emplean para su absorción intestinal y hepática a los OATP1Bs, pero la alta biodisponibilidad de estas moléculas sugiere que son pobres sustratos de la P-gp intestinal y del OATP1B3 hepático, responsables respectivos de la extrusión enterocítica y de la captación previa al primer paso hepático. No obstante, la escasa permeabilidad hematoencefálica y el hecho de que la rosiglitazona es muy buen sustrato de la P-gp placentaria ${ }^{45}$ indicaría lo contrario. El alto metabolismo hepático de las tiazolidindionas genera metabolitos conjugados de excreción biliar los cuales deberían usar la P-gp y la BCRP, pero al respecto no hay nada descripto.

\section{Inhibidores de la dipeptidil}

\section{peptidasa 4 (IDPP-4) o gliptinas}

Este conjunto de drogas tiene estructuras y farmacocinética heterogéneas ${ }^{46,47}$; como las glitazonas, su empleo conjunto con metformina mejora su rendimiento terapéutico. La absorción oral de las mismas es rápida (antes de las 2 hs dan el pico máximo) pero variable y los alimentos no influyen en la misma. La que menos biodisponibilidad registra es la linagliptina con sólo 30\%, le siguen la teneligliptina y saxagliptina con $70 \%$, la vildagliptina y sitagliptina con $85 \%$, y finalmente la alogliptina con $100 \%$. Salvo linagliptina y teneligliptina que exhiben alta unión proteica (80\%), el resto se une menos del 40\%. La linagliptina tiene un enorme volumen aparente de distribución, mientras que las demás exhiben un volumen de distribución un poco mayor al agua corporal. Lo comentado influye sobre el clearance y la vida media de eliminación que es sumamente larga para la linagliptina (130 hs), larga para la teneligliptina y alogliptina (24 hs) y corta (menos de 5 hs) para el resto. A pesar de la gran distribución las gliptinas pasan poco al tejido nervioso. Las gliptinas se metabolizan en el hígado (vía CYP3A4 principalmente) en grado sumamente variable, excepto la vildagliptina que lo hace por la DPP-4 y a nivel renal. La que más se metaboliza es la saxagliptina que da un metabolito activo, le siguen la teneligliptina y muy lejos, el resto. La excreción de droga y metabolitos es principalmente renal para la mayoría de las gliptinas (aprovechando filtración y secreción tubular activa, como la sitagliptina que casi no se metaboliza y el $90 \%$ se excreta activa por vía renal); la excepción son la teneligliptina que tiene un $50 \%$ de secreción bi- 
liar y la linagliptina que como se absorbe poco, se pierde por vía fecal predominantemente.

Las gliptinas no son inhibidoras o inductoras de los CYPs ${ }^{48}$ y, como ocurre con los otros antidiabéticos, existe escasa información sobre gliptinas y transportadores. La única descripción plena corresponde a la sitagliptina; algunos estudios indican que la droga afecta la efectividad de la metformina al usar también el OCT1 para incorporarse a las células y que entra a las células del túbulo contorneado proximal mediante el OAT3 y el OATP4C1 para ser secretado activamente por la P-gp apical $37,46,49$. Si esto se aplicara a toda la familia y se analizara junto con el comportamiento farmacocinético de cada gliptina podría especularse que la absorción de las mismas depende de los OATPs intestinales, que la entrada al hígado para el metabolismo y excreción se hace por el OCT1, que la entrada al túbulo renal se efectúa por el OAT3, y que la secreción biliar y renal la efectúa la P-gp. En este contexto, la baja biodisponibilidad de la linagliptina se explicaría por la expulsión enterocítica por la P-gp, hecho que no ocurre con el resto (o algo con la teneligliptina). Asimismo su bajo metabolismo dependería de la baja captación hepática seguida de una rápida expulsión por el polo biliar y, finalmente, su larga vida media se debería a la lenta acumulación intracelular en vesículas ácidas mediante las glicoproteínas $A B C$ de organelas (seguido de atrapamiento por su alto pK), tal como se verifica con el macrólido azitromicina.

\section{Inhibidores SGLT2 o gliflozinas}

Las gliflozinas (dapagliflozina, canagliflozina y empagliflozina) son el último grupo que se incorporó al arsenal terapéutico de la diabetes ${ }^{50}$. Estos compuestos se absorben a nivel intestinal rápidamente (en una hora y media se alcanza el pico máximo) con una biodisponibilidad del 65-80\%. Exhiben alta ligadura proteica (superior al $90 \%$ ) y gran volumen de distribución, aunque no atraviesan la barrera hematoencefálica. Estas drogas presentan gran eliminación mediante metabolismo de fase 2 (conjugación hepática con glucurónico) y filtración glomerular de la pequeña fracción libre (ésta sería suficiente como para ejercer su efecto desde la luz tubular) $)^{51-54}$. La dapagliflozina, a diferencia de las otras, filtra y se reabsorbe para ser conjugada a nivel renal y vuelta a secretar hacia la orina. La dapagliflozina es sustrato de los transportadores P-gp y OAT3 $^{55}$ lo que explica el comportamiento renal descripto (reabsorción OAT3 y secreción del conjugado mediante P-gp). La canagliflozina es sustratoinhibidor P-gp y sustrato MRP56. La empagliflozina es sustrato de los OATP1Bs, OAT3, P-gp y BCRP, sin embargo, carece de interacciones medicamentosas a nivel de estos transportadores ${ }^{52}$.

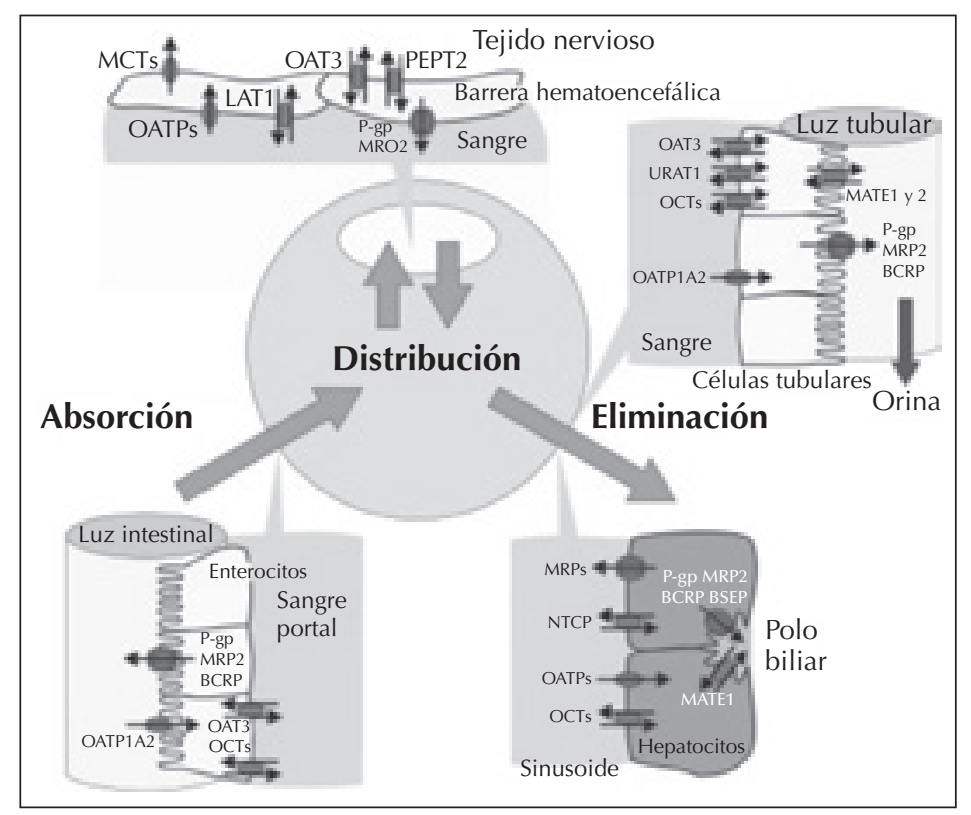

Figura 3: Procesos farmacocinéticos primarios, absorción, distribución y eliminación por excreción, y principales transportadores que operan sobre epitelios y tejidos. Éstos permiten los procesos mencionados al mover las drogas a través de las membranas limitantes de los compartimientos del organismo. 


\begin{tabular}{|c|c|c|c|c|}
\hline Nombre & $\begin{array}{l}\text { Sustrato } \\
\text { endógeno }\end{array}$ & $\begin{array}{c}\text { Drogas } \\
\text { transportadas } \\
\text { (-) significa inhibidor }\end{array}$ & $\begin{array}{l}\text { Expresión } \\
\text { tisular }\end{array}$ & Función \\
\hline $\begin{array}{l}\text { SLC7A5/3A2 } \\
\text { (LAT1) }\end{array}$ & $\begin{array}{l}\text { Aminoácidos grandes } \\
\text { (Trp x Cys) }\end{array}$ & $\begin{array}{l}\text { L-DOPA, T3, T4, pregabalina, } \\
\text { gabapentina }\end{array}$ & $\begin{array}{l}\text { Barrera } \\
\text { hematoencefálica }\end{array}$ & $\begin{array}{l}\text { IC: paso de aminoácidos } \\
\text { precursores al SNC }\end{array}$ \\
\hline $\begin{array}{l}\text { SLC7A8/3A2 } \\
\text { (LAT2) }\end{array}$ & $\begin{array}{l}\text { Aminoácidos neutros } \\
\text { (Leu x Gln) }\end{array}$ & T3, T4, pregabalina, gabapentina, melfalan & Ubicua, intestino, riñón & $\begin{array}{l}\text { IC: absorción de aminoácidos, } \\
\text { reabsorción tubular de los } \\
\text { mismos }\end{array}$ \\
\hline $\begin{array}{l}\text { SLC10A1 } \\
\text { (NTCP) }\end{array}$ & Sales biliares & Ursodesoxicólico, rosuvastatina & Hígado, intestino & $\begin{array}{l}\text { CTNa: reabsorción y ciclo } \\
\text { enterohepático de sales } \\
\text { biliares, drogas y afines }\end{array}$ \\
\hline $\begin{array}{l}\text { SLC10A6 } \\
\text { (SOAT) }\end{array}$ & $\begin{array}{l}\text { Sulfoconjugados aniónicos } \\
\text { de esteroides sexuales }\end{array}$ & Estrona sulfato, prasterona & $\begin{array}{l}\text { Gónadas, adrenal, } \\
\text { intestino, otros }\end{array}$ & $\begin{array}{l}\text { CTNa: distribución de } \\
\text { hormonas esteroides sexuales } \\
\text { y ciclo adrenogonadal }\end{array}$ \\
\hline $\begin{array}{l}\text { SLC15A1 } \\
\text { (PEPT1) }\end{array}$ & Di o tripéptidos & $\begin{array}{l}\text { Antibióticos betalactámicos, } \\
\text { betahistina, } \mathrm{Pl} \text {, IECA }\end{array}$ & Intestino, riñón, hígado & CTH: absorción de péptidos \\
\hline $\begin{array}{l}\text { SLC15A2 } \\
\text { (PEPT2) }\end{array}$ & Di o tripéptidos & Betalactámicos, ivermectina & $\begin{array}{l}\text { Plexos coroideos, bazo, } \\
\text { glándula mamaria, riñón }\end{array}$ & $\begin{array}{l}\text { CTH: eliminación } \\
\text { (excreción) de péptidos }\end{array}$ \\
\hline $\begin{array}{l}\text { SLC16A2 } \\
\text { (MCT8) }\end{array}$ & $\begin{array}{l}\text { Monocarboxilatos, } \\
\text { hormonas tiroideas }\end{array}$ & $\mathrm{T} 3, \mathrm{~T} 4$ & $\begin{array}{l}\text { Ubicuo, tejido nervioso, } \\
\text { corazón }\end{array}$ & $\begin{array}{l}\text { DF: incorporación celular } \\
\text { de hormonas tiroideas }\end{array}$ \\
\hline $\begin{array}{l}\text { SLC16A5 } \\
\text { (MCT6) }\end{array}$ & Monocarboxilatos & Diuréticos, nateglinida, probenecid (-) & $\begin{array}{l}\text { Riñón, músculo, tejido } \\
\text { nervioso, corazón, } \\
\text { pulmón }\end{array}$ & $\begin{array}{l}\text { CTH?: eliminación de } \\
\text { ácidos orgánicos (excreción } \\
\text { tubular de ácidos) }\end{array}$ \\
\hline $\begin{array}{l}\text { SLCO1A2 } \\
\text { (OATP1A2) }\end{array}$ & $\begin{array}{l}\text { Aniones y cationes } \\
\text { orgánicos complejos }\end{array}$ & $\begin{array}{l}\text { Macrólidos, rifamicinas (-), estatinas, T3, } \\
\text { T4, IECA, ARA2, beta-bloqueantes, glinidas, } \\
\text { psicofármacos en general, antihistamínicos, } \\
\text { antagonistas cálcicos, } \\
\text { alcaloides, PI (-), metotrexate, } \\
\text { glitazonas, trimetoprima, dipiridamol (-), } \\
\text { fungicidas, flavonoides (-), } \\
\text { sulfocompuestos (-) }\end{array}$ & Intestino, riñón & $\begin{array}{l}\text { DF?: absorción de } \\
\text { sustancias varias }\end{array}$ \\
\hline $\begin{array}{l}\text { SLCO1B1 y } 1 \mathrm{~B} 3 \\
\text { (OATP1B1 y 1B3) }\end{array}$ & $\begin{array}{l}\text { Bilirrubina y ácidos grasos } \\
\text { libres, ácidos biliares }\end{array}$ & $\begin{array}{l}\text { Ídem anterior excepto algunos } \\
\text { alcaloides, sulfodrogas, trimetoprima }\end{array}$ & Hígado (polo sanguíneo) & $\begin{array}{l}\text { DF?: captación de } \\
\text { sustancias para metabolismo } \\
\text { hepático (detoxificación } \\
\text { xenobiótica) }\end{array}$ \\
\hline $\begin{array}{l}\text { SLCO2B1 } \\
\text { (OATP2B1) }\end{array}$ & $\begin{array}{l}\text { Sulfoconjugados de } \\
\text { esteroides sexuales }\end{array}$ & $\begin{array}{l}\text { Ídem OATP1A2 más estrona sulfato, } \\
\text { prasterona }\end{array}$ & Hígado, intestino & $\begin{array}{l}\text { DF?: absorción-catabolismo } \\
\text { hepático de hormonas } \\
\text { esteroides }\end{array}$ \\
\hline $\begin{array}{l}\text { SLC22A1 y A2 } \\
(\mathrm{OCT} 1 \text { y } 2)\end{array}$ & Cationes orgánicos & $\begin{array}{l}\text { Metformina, IBPs, amiloride, } \\
\text { trimetoprima, gliptinas, } \\
\text { bloqueantes cálcicos y antiH2 }\end{array}$ & Intestino, riñón, hígado & $\begin{array}{l}\text { DF: absorción o } \\
\text { eliminación de cationes } \\
\text { orgánicos }\end{array}$ \\
\hline $\begin{array}{l}\text { SLC22A3 } \\
\text { (OCT3 o EMT) }\end{array}$ & $\begin{array}{l}\text { Cationes orgánicos, } \\
\text { catecolaminas }\end{array}$ & $\begin{array}{l}\text { Ídem anterior más aminas } \\
\text { simpáticomiméticas, } \\
\text { glucocorticoides (-) }\end{array}$ & Ubicua & $\begin{array}{l}\text { DF: distribución de } \\
\text { cationes, recaptación } 2 \text { o } \\
\text { extraneuronal }\end{array}$ \\
\hline $\begin{array}{l}\text { SLC22A8 } \\
\text { (OAT3) }\end{array}$ & $\begin{array}{l}\text { Aniones orgánicos } \\
\text { (anión } \mathrm{x} \text { lactato) }\end{array}$ & $\begin{array}{l}\text { AINEs, betalactámicos, aciclovir y otros } \\
\text { antivirales, quinolonas, } \\
\text { diuréticos, probenecid (-) }\end{array}$ & $\begin{array}{l}\text { Riñón, intestino, tejido } \\
\text { nervioso }\end{array}$ & $\begin{array}{l}\text { IC: eliminación de ácidos } \\
\text { orgánicos (excreción tubular } \\
\text { de ácidos) }\end{array}$ \\
\hline $\begin{array}{l}\text { SLC22A12 } \\
\text { (URAT1) }\end{array}$ & $\begin{array}{l}\text { Urato, aniones orgánicos } \\
\text { (urato } x \text { lactato) }\end{array}$ & $\begin{array}{l}\text { AINEs, ácido pirazinoico (-), } \\
\text { etambutol, probenecid }\end{array}$ & Riñón & $\begin{array}{l}\text { IC: regulación de la } \\
\text { uricemia (reabsorción, } \\
\text { excreción de urato) }\end{array}$ \\
\hline $\begin{array}{l}\text { SLC29A4 } \\
\text { (PMAT) }\end{array}$ & Cationes orgánicos y aminas & $\begin{array}{l}\text { Metformina, dipiridamol (-), aminas simpá- } \\
\text { ticomiméticas, nucleósidos }\end{array}$ & $\begin{array}{l}\text { Corazón, riñón, múscu- } \\
\text { lo, tejido nervioso }\end{array}$ & $\begin{array}{l}\text { CTH?: distribución y } \\
\text { eliminación de monoaminas }\end{array}$ \\
\hline $\begin{array}{l}\text { SLC47A1 } \\
\text { (MATE1) }\end{array}$ & $\begin{array}{l}\text { Cationes orgánicos, } \\
\text { creatinina, estrona sulfato }\end{array}$ & $\begin{array}{l}\text { Metformina y guanidinas, bloqueantes } \mathrm{H} 2 \text {, } \\
\text { trimetoprima, procainamida y antiarrítmicos } \\
\text { de clase Ic, anestésicos locales amidas, } \\
\text { alcaloides, IBPs, ITK, piperazinas y pipe- } \\
\text { ridinas, topotecan, aciclovir y derivados, } \\
\text { cefalosporinas de tercera generación, azoles }\end{array}$ & $\begin{array}{l}\text { Hígado, intestino, riñón, } \\
\text { adrenal }\end{array}$ & $\begin{array}{l}\text { CTH?: distribución y } \\
\text { eliminación metabólica de } \\
\text { compuestos catiónicos }\end{array}$ \\
\hline $\begin{array}{l}\text { SLC47A2 } \\
\text { (MATE2-K) }\end{array}$ & Ídem anterior & $\begin{array}{l}\text { Ídem anterior más metales pesados (com- } \\
\text { puestos de platino) }\end{array}$ & Riñón & $\begin{array}{l}\text { CTH?: eliminación de bases } \\
\text { orgánicas (excreción tubular } \\
\text { de bases) }\end{array}$ \\
\hline
\end{tabular}

Tabla 1: Principales familias SLC involucradas en la farmacocinética de drogas (modificado de Alexander SPH, et al. ${ }^{6}$ y Giacomini KM, et al. ${ }^{8}$. 
Referencias: Nombre (según orden de aparición): LAT (large neutral amino acid transporter), transportador de aminoácidos grandes y neutros; NTCP (Na-taurocholate cotransporting polipeptide), polipéptido cotransportador de $\mathrm{Na}^{+}$y taurocolato; SOAT (sodiumdependent organic anion transporter), transportador de aniones orgánicos dependiente de $\mathrm{Na}^{+}$; PEPT (peptide transporter), transportador de péptidos; MCT (monocarboxilate transporter), transportador de monocarboxilatos; OATP (organic anion transporting oligopeptide), oligopéptido transportador de aniones orgánicos; OCT (organic cation transporter), transportador de cationes orgánicos; EMT (extraneuronal monoamine transporter), transportador extraneuronal de monoaminas; OAT (organic anion transporter), transportador de aniones orgánicos; URAT (urate transporter), transportador de urato; PMAT (plasma-membrane monoamine transporter), transportador de monoaminas de la membrana plasmática; MATE (multidrug and toxic-compound extrusion), proteína extrusora de múltiples drogas y toxinas.

Drogas transportadas: AINEs, antiinflamatorios no esteroides; ARA2, antagonistas del receptor a angiotensina II; IBPs, inhibidores de la bomba de protones; IECA, inhibidores de la enzima convesora de angiotensina; ITK, inhibidores de las tirosina quinasas; PI, inhibidores de la proteasa. Función (el signo ? indica función poco precisada o supuesta): CTH, cotransporte protón dependiente; CTNa, cotransporte dependiente de $\mathrm{Na}+$; DF, difusión facilitada; IC, intercambiador (en el sustrato se indica el intercambio de sustrato).

\begin{tabular}{|c|c|c|c|c|}
\hline Nombre & $\begin{array}{c}\text { Sustrato } \\
\text { endógeno }\end{array}$ & $\begin{array}{c}\text { Drogas } \\
\text { transportadas } \\
\text { (-) significa inhibidor }\end{array}$ & $\begin{array}{l}\text { Expresión } \\
\text { tisular }\end{array}$ & Función \\
\hline $\begin{array}{l}\text { ABCB1 } \\
\text { (MDR1 o P-gp) }\end{array}$ & Xenobióticos básicos & $\begin{array}{l}\text { Antagonistas cálcicos (-), sulfodrogas, } \\
\text { gliptinas, glitazonas, anticoagulantes, } \\
\text { alcaloides y glucósidos, PI (-), azoles (-), la } \\
\text { mayoría de los antibióticos especialmente } \\
\text { macrólidos (-), glicopéptidos y poliénicos }\end{array}$ & $\begin{array}{l}\text { Casi ubicua, intestino, } \\
\text { riñón, hígado, barrera } \\
\text { hematoencefálica, } \\
\text { placenta }\end{array}$ & $\begin{array}{l}\text { Eliminación (excreción) } \\
\text { de xenobióticos básicos }\end{array}$ \\
\hline $\begin{array}{l}\mathrm{ABCC} 1 \\
\text { (MRP1) }\end{array}$ & $\begin{array}{l}\text { Endo (leucotrienos, ácidos } \\
\text { grasos, bilirrubina, folato, } \\
\text { esteroides) y } \\
\text { xenobióticos ácidos, } \\
\text { compuestos conjugados con } \\
\text { glutatión o glucurónidos }\end{array}$ & $\begin{array}{l}\text { Metotrexato, quinolonas, esteroides } \\
\text { sulfoconjugados, betalactámicos, algunos } \\
\text { conjugados glucurónidos }\end{array}$ & Ubicua & $\begin{array}{l}\text { Secreción de leucotrienos; } \\
\text { eliminación (excreción) } \\
\text { de endo y xenobióticos ácidos } \\
\text { libres o conjugados; } \\
\text { distribución de hormonas } \\
\text { esteroides sexuales y ciclo } \\
\text { adrenogonadal }\end{array}$ \\
\hline $\begin{array}{l}\mathrm{ABCC} 2 \\
(\mathrm{MRP} 2)\end{array}$ & $\begin{array}{l}\text { Ídem anterior más sales } \\
\text { biliares }\end{array}$ & $\begin{array}{l}\text { Las mismas que } \mathrm{ABCC} 1 \text { más estatinas, } \mathrm{PI} \\
\text { IECA, ARA2, glifozinas }\end{array}$ & Hígado, riñón, intestino & $\begin{array}{l}\text { Eliminación (excreción) de } \\
\text { bilirrubina conjugada }\end{array}$ \\
\hline $\begin{array}{l}\mathrm{ABCC} 3 \\
(\mathrm{MRP} 3)\end{array}$ & $\begin{array}{l}\text { Ídem anterior excepto que } \\
\text { es menos afín por los } \\
\text { conjugados con glutation }\end{array}$ & $\begin{array}{l}\text { La mayoría de las drogas y metabolitos } \\
\text { conjugados con ácido glucurónico (por } \\
\text { ejemplo, glucurónidos de morfina, de } \\
\text { paracetamol, de esteroides) }\end{array}$ & Ídem anterior & No definida \\
\hline $\begin{array}{l}\text { ABCC4 y } 5 \\
(\mathrm{MRP} 4 \text { y } 5)\end{array}$ & $\begin{array}{l}\text { Nucleótidos (lineales y } \\
\text { cíclicos) }\end{array}$ & $\begin{array}{l}\text { Análogos de bases antivirales y anti- } \\
\text { neoplásicos, allopurinol, diuréticos de asa, } \\
\text { metotrexato y derivados, cefalosporinas, } \\
\text { esteroides sulfoconjugados, PI }\end{array}$ & Ubicua & $\begin{array}{l}\text { Terminación de } \\
\text { señalización }\end{array}$ \\
\hline $\begin{array}{l}\text { ABCG2 } \\
\text { (BCRP) }\end{array}$ & Hemo & $\begin{array}{l}\text { Muchos alcaloides y antibióticos anti- } \\
\text { neoplásicos, esteroides sulfoconjugados, } \\
\text { quinolonas, dantroleno, sulfazalazina, } \\
\text { fitoestrógenos, sulfonilureas, glitazonas, } \\
\text { glifozinas, nitrocompuestos, rosuvastatina, } \\
\text { inhibidores tirosina quinasa }\end{array}$ & $\begin{array}{l}\text { Hígado, intestino, } \\
\text { médula ósea, barrera } \\
\text { hematoencefálica }\end{array}$ & $\begin{array}{l}\text { Transporte del hemo } \\
\text { durante la eritropoyesis }\end{array}$ \\
\hline
\end{tabular}

Tabla 2: Principales familias ABC involucradas en la farmacocinética de drogas (modificado de Alexander SPH, et al. ${ }^{6} \mathrm{y}$ Giacomini KM, et al. ${ }^{8}$.

Referencias: Nombre (según orden de aparición): MDR (multidrug resistance), resistencia múltiple a drogas (descripto inicialmente como fenotipo de resistencia antitumoral); P-gp (P glycoprotein), glicoproteína P (es la responsable del fenotipo MDR); MRP (multidrug resistance protein), proteína de resistencia múltiple a drogas; BCRP (breast cancer resistant protein), proteína de resistencia del cáncer de mama. Drogas transportadas: ídem Tabla 1. 


\begin{tabular}{|c|c|c|c|c|c|}
\hline $\begin{array}{c}\text { Antidiabético } \\
\text { oral }\end{array}$ & $\begin{array}{l}\text { Segunda droga } \\
\text { (característica) }\end{array}$ & $\begin{array}{l}\text { Transportador } \\
\text { involucrado }\end{array}$ & Efecto final & Importancia clínica (conducta) & Referencia \\
\hline \multirow{7}{*}{ Metformina } & Quinidina (sustrato) & OCT1 hepático & $\begin{array}{l}\text { Inhibe ingreso a las células blanco } \\
\text { (disminuye el efecto) }\end{array}$ & \multirow{6}{*}{$\begin{array}{l}\text { Menor si la función renal está conservada } \\
\text { (no hacer nada o ajustar la dosis de } \\
\text { metformina si es necesario) } \\
\text { Mayor si hay insuficiencia parenquima- } \\
\text { tosa, anemia, infecciones o situaciones } \\
\text { predisponentes de hipoxia por el riesgo } \\
\text { de acidosis láctica (suspender inmediata- } \\
\text { mente la metformina y rever tratamientos) }\end{array}$} & 57 \\
\hline & $\begin{array}{l}\text { Beta-bloqueantes, } \\
\text { fenfluramina, } \\
\text { mexiletina (sustratos) }\end{array}$ & OCT2 renal & $\begin{array}{l}\text { Inhiben el ingreso de metformina a } \\
\text { las células tubulares (disminuyen el } \\
\text { clearance) }\end{array}$ & & 58,59 \\
\hline & $\begin{array}{l}\text { Cloroquina y derivados, } \\
\text { cefalosporinas de prime- } \\
\text { ra generación (sustratos), } \\
\text { tacrolimus (inhibidor) }\end{array}$ & MATE1 renal & $\begin{array}{l}\text { Inhiben la secreción tubular de } \\
\text { metformina } \\
\text { (disminuyen el clearance) }\end{array}$ & & 60,61 \\
\hline & $\begin{array}{l}\text { Inhibidores de la } \\
\text { proteasa, dipiridamol, } \\
\text { ketoconazol y otros } \\
\text { imidazoles (inhibidores), } \\
\text { antifólicos, bloqueantes } \\
\text { H2 (sustratos) }\end{array}$ & $\begin{array}{l}\text { OCT2 y MATE1 } \\
\text { renales }\end{array}$ & $\begin{array}{l}\text { Inhiben el ingreso de metformina a } \\
\text { las células tubulares y su secreción } \\
\text { (disminuyen el clearance) }\end{array}$ & & $61-63$ \\
\hline & $\begin{array}{l}\text { Diuréticos ahorradores } \\
\text { de } \mathrm{K}^{+} \text {no esteroides } \\
\text { (sustratos) }\end{array}$ & $\begin{array}{l}\text { OCT3, MATE1 y } \\
2-K \text { renales }\end{array}$ & $\begin{array}{l}\text { Inhiben el ingreso de metformina a } \\
\text { las células tubulares y su secreción } \\
\text { (disminuyen el clearance) }\end{array}$ & & 64 \\
\hline & $\begin{array}{l}\text { Inhibidores, tirosina } \\
\text { quinasa (inhibidores) }\end{array}$ & $\begin{array}{l}\text { OCT1 y } 3 \text { gene- } \\
\text { rales MATE1 y } \\
\text { 2-K renales }\end{array}$ & $\begin{array}{l}\text { Inhiben el ingreso de metformina } \\
\text { a las células y su secreción tubular } \\
\text { (disminuyen la absorción, el efecto } \\
\text { y el clearance) }\end{array}$ & & 59,65 \\
\hline & Verapamilo (inhibidor) & P-gp placentaria & $\begin{array}{l}\text { Disminuye mínimamente la salida } \\
\text { celular de metformina (hecho en } \\
\text { cultivos placentarios) }\end{array}$ & $\begin{array}{l}\text { No aplicable el verapamilo; está } \\
\text { contraindicado en el embarazo }\end{array}$ & 45 \\
\hline \multirow{10}{*}{ Sulfonilureas } & $\begin{array}{l}\text { Rifampicina intravenosa } \\
\text { al inicio (sustrato) }\end{array}$ & $\begin{array}{l}\text { OATP1B1 } \\
\text { hepático }\end{array}$ & $\begin{array}{l}\text { Disminuye la captación y } \\
\text { el metabolismo hepático de } \\
\text { glibenclamida (aumenta 2-3 veces } \\
\text { el AUC) }\end{array}$ & $\begin{array}{l}\text { No aplicable pues el antibiótico no se } \\
\text { usa de esa forma, aunque exista riesgo } \\
\text { de hipoglucemia en agudo }\end{array}$ & 66 \\
\hline & $\begin{array}{l}\text { Extracto de Ginkgo, } \\
\text { jugos cítricos } \\
\text { (inhibidores) }\end{array}$ & $\begin{array}{l}\text { OATP2B1 } \\
\text { intestinal }\end{array}$ & $\begin{array}{l}\text { Inhiben la absorción de glibencla- } \\
\text { mida (nada o menor efecto) }\end{array}$ & Menor (ajustar la dosis si es necesario) & $41,67,68$ \\
\hline & $\begin{array}{l}\text { Estrona } 3 \text { sulfato } \\
\text { (sustrato) }\end{array}$ & $\begin{array}{l}\text { OATP2B1 } \\
\text { intestinal }\end{array}$ & $\begin{array}{l}\text { Se inhibe la absorción de ambos o } \\
\text { el ciclo enterohepático del esteroi- } \\
\text { de (menor efecto) }\end{array}$ & $\begin{array}{l}\text { Menor (ajustar las dosis de los } \\
\text { interactuantes si es necesario) }\end{array}$ & 69 \\
\hline & Estatinas (sustratos) & $\begin{array}{l}\text { OATP2B1 intesti- } \\
\text { nal y OATP1B1 } \\
\text { hepático }\end{array}$ & $\begin{array}{l}\text { Se inhibe la absorción de ambas } \\
\text { clases o la captación hepática de } \\
\text { las estatinas (menor efecto) }\end{array}$ & $\begin{array}{l}\text { Menor (ajustar las dosis de los } \\
\text { interactuantes si es necesario) }\end{array}$ & $69-71$ \\
\hline & $\begin{array}{l}\text { Claritromicina } \\
\text { (inhibidor) }\end{array}$ & P-gp intestinal & $\begin{array}{l}\text { Inhibe la expulsión intestinal de } \\
\text { glibenclamida (aumenta levemente } \\
\text { Cmax y AUC) }\end{array}$ & $\begin{array}{l}\text { Intermedia con riesgo de hipoglucemia } \\
\text { leve (ajustar la dosis de la sulfonilurea) }\end{array}$ & 68 \\
\hline & Colchicina (sustrato) & P-gp intestinal & $\begin{array}{l}\text { Por la inhibición de la glibenclami- } \\
\text { da, aumentan los niveles intrace- } \\
\text { lulares del alcaloide (potenciación } \\
\text { de su toxicidad intestinal) }\end{array}$ & $\begin{array}{l}\text { Mayor (evitar el uso de colchicina junto } \\
\text { con sulfonilureas, puede hacerse exten- } \\
\text { sivo a ergotamina por posible ergotismo } \\
\text { al incrementar su absorción) }\end{array}$ & 39 \\
\hline & $\begin{array}{l}\text { Rifampicina en forma } \\
\text { crónica,hipérico-hierba } \\
\text { de San Juan } \\
\text { (inductores) }\end{array}$ & $\begin{array}{l}\text { P-gp intestinal y } \\
\text { hepático }\end{array}$ & $\begin{array}{l}\text { Aumentan la expulsión de sulfo- } \\
\text { nilureas junto con su catabolismo } \\
\text { (aumenta el clearance y se pierde } \\
\text { efecto) }\end{array}$ & $\begin{array}{l}\text { Intermedia (evaluar respuesta y } \\
\text { suspender o remplazar los compuestos } \\
\text { inductores) }\end{array}$ & 64,66 \\
\hline & Indometacina (sustrato) & $\begin{array}{l}\text { MRP1 y } 3 \\
\text { placentarios }\end{array}$ & $\begin{array}{l}\text { Disminuye la actividad de las bom- } \\
\text { bas (hecho en cultivos de placenta, } \\
\text { aumenta la acumulación intracelular } \\
\text { de la sulfonilurea) }\end{array}$ & $\begin{array}{l}\text { No aplicable; las sulfonilureas están } \\
\text { contraindicadas en el embarazo }\end{array}$ & 45,72 \\
\hline & $\begin{array}{l}\text { Dihidropiridinas } \\
\text { (inhibidores) }\end{array}$ & BCRP placentaria & $\begin{array}{l}\text { Disminuye la actividad de la } \\
\text { bomba (hecho en cultivos de } \\
\text { placenta, aumenta la acumulación } \\
\text { intracelular de la sulfonilurea) }\end{array}$ & Ídem & 40 \\
\hline & $\begin{array}{l}\text { Ácidos biliares } \\
\text { (sustratos) }\end{array}$ & $\begin{array}{l}\text { NCTP-BSEP } \\
\text { hepático }\end{array}$ & $\begin{array}{l}\text { Las sulfonilureas disminuyen la } \\
\text { secreción biliar }\end{array}$ & $\begin{array}{l}\text { Menor, riesgo de ictericia (evitar el } \\
\text { empleo conjunto) }\end{array}$ & 73,74 \\
\hline
\end{tabular}




\begin{tabular}{|c|c|c|c|c|c|}
\hline $\begin{array}{c}\text { Antidiabético } \\
\text { oral }\end{array}$ & $\begin{array}{l}\text { Segunda droga } \\
\text { (característica) }\end{array}$ & $\begin{array}{l}\text { Transportador } \\
\text { involucrado }\end{array}$ & Efecto final & Importancia clínica (conducta) & Referencia \\
\hline Glinidas & $\begin{array}{l}\text { Estatinas, } \\
\text { claritromicina, } \\
\text { ciclosporina A, } \\
\text { gemfibrozil } \\
\text { (sustratos) }\end{array}$ & $\begin{array}{l}\text { OATP1B1 y } 1 \text { B3 } \\
\text { hepáticos }\end{array}$ & $\begin{array}{l}\text { Aumentan los niveles plasmáticos } \\
\text { de repaglinida por menor cap- } \\
\text { tación y metabolismo, riesgo de } \\
\text { hipoglucemia }\end{array}$ & $\begin{array}{l}\text { Menor con estatinas o claritromicina } \\
\text { (no hacer nada o ajustar la dosis) } \\
\text { Mayor con ciclosporina A y gemfibrozil } \\
\text { pues al ser también inhibidores impor- } \\
\text { tantes del CYP3A4 los niveles plasmáti- } \\
\text { cos de repaglinida son } 3 \text { a } 8 \text { veces más } \\
\text { altos con el uso concomitante (evitar el } \\
\text { uso conjunto) }\end{array}$ & $75-78$ \\
\hline \multirow{3}{*}{ Glitazonas } & $\begin{array}{l}\text { Estradiol } 17 \\
\text { glucurónido, } \\
\text { estrona } 3 \text { sulfato } \\
\text { (sustratos) }\end{array}$ & $\begin{array}{l}\text { OATP1B1 } \\
\text { hepático }\end{array}$ & $\begin{array}{l}\text { Inhiben la captación hepática } \\
\text { y el metabolismo del esteroide, } \\
\text { menor efecto y reducción del ciclo } \\
\text { enterohepático }\end{array}$ & $\begin{array}{l}\text { Menor (no hacer nada o ajustar dosis) } \\
\text { Interacción extrapolable a anticoncep- } \\
\text { tivos orales y tamoxifeno (puede haber } \\
\text { falta de eficacia por fracaso del ciclo) }\end{array}$ & 77,78 \\
\hline & Estatinas (sustratos) & $\begin{array}{l}\text { OATP1B1 y 1B3 } \\
\text { hepáticos }\end{array}$ & $\begin{array}{l}\text { Inhiben la captación hepática de } \\
\text { las estatinas (menor efecto) }\end{array}$ & Menor (ajustar la dosis) & 79 \\
\hline & $\begin{array}{l}\text { Ácidos biliares } \\
\text { (sustratos) }\end{array}$ & $\begin{array}{l}\text { NCTP-BSEP } \\
\text { hepáticos }\end{array}$ & $\begin{array}{l}\text { Las glitazonas disminuyen la } \\
\text { secreción biliar }\end{array}$ & $\begin{array}{l}\text { Menor, riesgo de ictericia (evitar el } \\
\text { empleo conjunto) }\end{array}$ & 73,74 \\
\hline \multirow{4}{*}{ Gliptinas } & Metformina (sustrato) & OCT1 hepático & $\begin{array}{l}\text { La sitagliptina inhibe ingreso de } \\
\text { metformina (menor efecto) }\end{array}$ & Menor (no hacer nada) & 80 \\
\hline & $\begin{array}{l}\text { Diuréticos de asa } \\
\text { AINEs, } \\
\text { ácido fenofíbrico, } \\
\text { quinapril, } \\
\text { cimetidina, } \\
\text { valsartán } \\
\text { (sustratos) }\end{array}$ & OAT3 renal & $\begin{array}{l}\text { Las drogas mencionadas inhiben el } \\
\text { ingreso de sitagliptina a las células } \\
\text { tubulares y vildagliptina hace lo } \\
\text { propio con el valsartán (menor } \\
\text { clearance) }\end{array}$ & $\begin{array}{l}\text { Menor (ajustar las dosis de los } \\
\text { interactuantes si es necesario) }\end{array}$ & 49,81 \\
\hline & $\begin{array}{l}\text { Bloqueantes } \mathrm{H} 2 \\
\text { (sustratos) }\end{array}$ & OCT1 y 2 renales & $\begin{array}{l}\text { Inhiben el ingreso de ambas } \\
\text { clases a las células tubulares (menor } \\
\text { clearance) }\end{array}$ & $\begin{array}{l}\text { Menor (ajustar las dosis de ambas según } \\
\text { necesidad) }\end{array}$ & 49 \\
\hline & $\begin{array}{l}\text { Ciclosporina A } \\
\text { (inhibidor), } \\
\text { digoxina } \\
\text { (sustrato) }\end{array}$ & $\begin{array}{l}\text { P-gp intestinal y } \\
\text { renal }\end{array}$ & $\begin{array}{l}\text { La ciclosporina aumenta la absor- } \\
\text { ción y reduce la secreción tubular } \\
\text { de sitagliptina y ésta hace lo propio } \\
\text { con digoxina (menor clearance) }\end{array}$ & Menor (ajustar las dosis si es necesario) & 48,49 \\
\hline Gliflozinas & $\begin{array}{l}\text { Digoxina, } \\
\text { dabigatrán } \\
\text { (sustratos) }\end{array}$ & P-gp intestinal & $\begin{array}{l}\text { La canagliflozina (inhibidor) puede } \\
\text { aumentar la absorción intestinal } \\
\text { (riesgo de sangrado con el anticoa- } \\
\text { gulante) }\end{array}$ & $\begin{array}{l}\text { Menor, pero observar (ajustar las dosis } \\
\text { si es necesario) }\end{array}$ & 56 \\
\hline
\end{tabular}

Tabla 3: Interacciones medicamentosas de los principales grupos de antidiabéticos orales a nivel de los transportadores.

Referencias: AUC, área bajo la curva concentración tiempo; BSEP (bile salt export pump), bomba extrusora de sales biliares; Cmax, concentración máxima; NTCP (Na-taurocholate cotransporting polipeptide), polipéptido cotransportador de sodio y taurocolato. Las demás siglas igual que en la Tabla 1. 


\section{CONCLUSIONES}

En la actualidad el alcance de los objetivos glucémicos en personas con DM2 requiere frecuentemente la combinación de varios fármacos orales. Se agrega, además, la necesidad de incorporar otros, también de uso oral, para el control de los objetivos no glucémicos como ser el de la hipertensión arterial o el de la dislipemia. Todos ellos, muchas veces sumados además al resto de tratamientos por distintas complicaciones o comorbilidades, hacen que frecuentemente esta población se encuentre polimedicada. Así, el "viaje propuesto" para las moléculas de drogas por el organismo se halla complicado.

En este contexto es necesario evaluar no sólo los efectos adversos propios de las drogas sino también las posibles interacciones farmacocinéticas que muchas veces son riesgosas y que si no son contempladas apropiadamente conducen inexorablemente a una morbimortalidad inaceptable y prevenible. Riesgos que no sólo dependen de las fases farmacocinéticas sino de la falta de eficacia y de la toxicidad.

Para el tema bajo estudio en este artículo todavía no existe suficiente información del impacto clínico sobre la competencia de los distintos transportadores y sus respectivos fármacos sustrato. Y, obviamente, cuanto más nuevos son los fármacos, menos información hay. Debido a que un fármaco dado puede inhibir la entrada o salida de otro en un determinado tejido y esto puede alterar su respuesta terapéutica, se producen situaciones que no deben ignorarse bajo ningún concepto. Usando la información disponible, pueden construirse modelos cinéticos (como la interpretación relatada sobre la absorción de la linagliptina) que den cabida a interacciones probables de gran importancia clínica, aunque no estén aún descriptas.

La Tabla 3 muestra las interacciones descriptas con los antidiabéticos orales a nivel de los transportadores; se destaca que la mayoría es de importancia menor y que no obliga a grandes cambios en los esquemas terapéuticos. Sin embargo, deben tenerse en cuenta dos aspectos: salvo metformina y algunas gliptinas, los antidiabéticos orales sufren importante metabolismo con interacciones relevantes a ese nivel que se suman a la hora de la interpretación clínica del paciente. Existen situaciones individuales (etnias, género, edad) y patológicas (insuficiencias parenquimatosas, infecciones, la propia diabetes) que cambian la farmacocinética y la farmacodinámica estándar de las moléculas empleadas como terapéutica, y por ello una interacción juzgada como menor puede ser absolutamente mayor (severa) en alguno de los contextos relatados. Por ello, la interpretación de los datos de la tabla debe tomarse con reparos y evaluar cada situación particular si han de aplicarse a la terapia.

Una debilidad de esta revisión es que muchas interacciones descriptas parten de estudios in vitro y aunque el resultado podría extrapolarse al hombre, siempre debe considerarse que son modelos de estudio y, justamente un modelo es un modelo y su interpretación podrá variar en el futuro al confirmar o descartar conceptos según la nueva información que se acumule. Por ello, creemos que el estudio y formación constante del profesional son las claves para derribar barreras, y esto es justamente lo que hacen los transportadores con sus sustratos: allanan caminos.

\section{REFERENCIAS}

1. Inzucchi SE, Bergenstal RM, Buse JB, et al. Management of hyperglycemia in type 2 diabetes, 2015. A patient-centered approach: update to a position statement of the American Diabetes Association and the European Association for the Study of Diabetes. Diabetes Care 2015;3 8: 140-9.

2. Tahrani AA, Bailey CJ, Del Prato S, et al. Management of type 2 diabetes: new and future developments in treatment. Lancet 2011; 378(9786): 182-97.

3. Ponte ML, Wachs L, Wachs A, Serra HA. Prescribing cascade. A proposed new way to evaluate it. Medicina (Buenos Aires) 2017; 77: 13-16.

4. Gravelle S, Joly L, Detcheverry F, Ybert C, Cottin-Bizonne C, Bocquet L. Optimizing water permeability through the hourglass shape of aquaporins. PNAS 2013; 110: 16367-72.

5. Alexander SPH, Kelly E, Marrion N, Peters JA, Benson HE, Faccenda $\mathrm{E}$, et al. The Concise Guide to PHARMACOLOGY 2015/16: Overview. Br J Pharmacol 2015; 172: 5729-43.

6. Alexander SPH, Kelly E, Marrion N, Peters JA, Benson HE Faccenda $E$, et al. The Concise Guide to PHARMACOLOGY 2015/16: Transporters. Br J Pharmacol 2015; 172: 6110-202.

7. Schumacher T, Benndorf RA. ABC transport proteins in cardiovascular disease-a brief summary. Molecules 2017; 22 pii: E589.

8. Giacomini KM, Sugiyama Y. Transportadores de membrana y respuesta a los fármacos. En: Brunton L, Chabner B, Knollman B, Eds. Goodman \& Gilman. Las bases farmacológicas de la terapéutica. 12 Ed. México: Mc Graw-Hill Interamericana 2012; 89-121.

9. González F, Coughtrie M, Tukey RH. Metabolismo de los fármacos. En: Brunton L, Chabner B, Knollman B, Eds. Goodman \& Gilman. Las bases farmacológicas de la terapéutica. 12 Ed. México: Mc Graw-Hill Interamericana 2012; 123-43.

10. Nigam SK. What do drug transporters really do? Nat Rev Drug Dis 2015; 14: 29-44.

11. He L, Vasiliou K, Nerbert DW. Analysis and update of the human solute carrier (SLC) gene superfamily. Hum Genomics 2009; 2: 195-206. 
12. Schlessinger A, Khuri N, Giacomini KM, Sali A. Molecular modeling and ligand docking for solute carrier (SLC) transporters. CurrTop Med Chem 2013; 13: 843-56.

13. Colasa C, Unga PM, Schlessinger A. SLC transporters: structure, function, and drug discovery. Med Chem Comm 2016; 7: 1069-81.

14. Reyes N, Ginter C, Boudker O. Transport mechanism of a bacterial homologue of glutamate transporters. Nature 2009; 462: 880-5.

15. Palacín $M$, Nunes $V$, Font-Llitjós $M$, et al. The genetics of heteromeric amino acid transporters. Physiology 2005; 20: 112-24.

16. Fotiadis D, Kanai Y, Palacín M. The SLC3 and SLC7 families of amino acid transporters. Mol Aspects Med 2013; 34: 139-58.

17. Wilkens $S$. Structure and mechanism of $A B C$ transporters. $F$ 1000 Prime Reports 2015; 7: 14. doi:10.12703/P7-14. eCollection 2015.

18. Gomperts BD, Tatham PER, Kramer IM. Signal Transduction. London: Elsevier Academic Press. 2002.

19. Palma AG, Kotsias BA, Marino GI. Funciones de los canales iónicos CFTR y ENAC en la fibrosis quística. Medicina (Bs As) 2014; 74: 133-9.

20. Vasiliou V, Vasiliou K, Nebert DW. Human ATP-binding cassette (ABC) transporter family. Hum Genomics 2009; 3: 281-90.

21. Iannantuono RF, Serra HA, Zieher LM. Farmacocinética I: absorción, distribución y eliminación de fármacos. En: Zieher LM y col, Eds. Farmacología General y de la Neurotransmisión, $3^{\circ}$ Ed. Buenos Aires: Librería Ursino 2003; 1-24.

22. Guías para el tratamiento de la diabetes mellitus tipo 2. Sociedad Argentina de Diabetes AC; 2016

23. Graham GG, Punt J, Arora M, Day RO, Doogue MP, Duong JK, et al. Clinical pharmacokinetics of metformin. Clin Pharmacokinet 2011; 50: 81-98.

24. Stepensky D, Friedman M, Raz I, Hoffman A. Pharmacokineticpharmacodynamic analysis of the glucose-lowering effect of metformin in diabetic rats reveals first-pass pharmacodynamic effect. Drug Metab Dispos 2002; 30: 861-8.

25. Gong L, Goswami S, Giacomini KM, Altman RB, KleinaTE. Metformin pathways: pharmacokinetics and pharmacodynamics. Pharmacogenet Genomics 2012; 22: 820-7.

26. Song NN, Li QS, Liu CX. Intestinal permeability of metformin using single-pass intestinal perfusion in rats. World J Gastroenterol 2006; 12: 4064-70.

27. ShuY, Brown C, Castro RA, Shi RJ, Lin ET, Owen RP, et al. Effect of genetic variation in the organic cation transporter 1, OCT1, on metformin pharmacokinetics. Clin Pharmacol Ther 2008; 83: 273-80

28. Serra HA, Rizzo LF. Point to note on the metformin absorption. 4th International Congress on Prediabetes and the Metabolic Syndrome. Madrid; 2011.

29. Scarpello JH, Howlett HC. Metformin therapy and clinical uses. Diab Vasc Dis Res 2008; 5:157-167.

30. Bailey CJ, Wilcock C, Scarpello JH. Metformin and the intestine. Diabetologia 2008; 51:1552-1553.

31. Parra D, Legreid AM, Beckey NP, Reyes S. Metformin monitoring and change in serum creatinine levels in patients undergoing radiologic procedures involving administration of intravenous contrast media. Pharmacotherapy 2004; 24: 987-93.

32. Nies AT, Koepsell H, Damme K, et al. Organic cation transporters (OCTs, MATEs) in vitro and in vivo evidence for the importance in drug therapy. Handb Exp Pharmacol 2011; 105-167.

33. Glucophage (metformin hydrochloride) US prescribing information. Bristol-Myers Squibb Company April 5, 2017.
34. Radwan MA, AITaweel ES, Al-Moghairi AM, Aloudah NM, Al Babtain MA, Al-Amri HS. Monitoring metformin in cardiac patients exposed to contrast media using ultra-high-performance liquid chromatography tandem mass-spectrometry. Ther Drug Monit 2011; 33: 742-9.

35. Sola D, Rossi L, Carnevale-Schianca GP, Maffioli P, Bigliocca M, Mella $\mathrm{R}$, et al. Sulfonylureas and their use in clinical practice. Arch Med Sci 2015; 12: 840-8.

36. Li X, Liu ZQ. Pharmacogenetic factors that affect drug metabolism and efficacy in type 2 diabetes mellitus. In: Xie W, ed. Drug metabolism in diseases. Amsterdam: Elsevier Academic Press 2017; 157-79.

37. Klatt S, Fromm MF, König J.Transporter-mediated drug-drug interactions with oral antidiabetic drugs. Pharmaceutics 2011; 3 : 680-705.

38. Gedeon C, Behravan J, Koren G, Piquette-Miller M. Transport of glyburide by placental $A B C$ transporters: implications in fetal drug exposure. Placenta 2006; 27: 1096-102.

39. Golstein PE, Boom A, van Geffel J, Jacobs P, Masereel B, Beauwens R. P-glycoprotein inhibition by glibenclamide and related compounds. Pflugers Arch 1999; 437: 652-60.

40. Pollex E, Lubetsky A, Koren, G. The role of placental breast cancer resistance protein in the efflux of glyburide across the human placenta. Placenta 2008; 29: 743-7.

41. Satoh H, Yamashita F, Tsujimoto M, Murakami H, Koyabu N, Ohtani $\mathrm{H}$, et al. Citrus juices inhibit the function of human organic anion-transporting polypeptide OATP-B. Drug Metab Dispos 2005; 33: 518-23.

42. Guardado-Mendoza R, Prioletta A, Jiménez-Ceja LM, Sosale A, Folli $F$. The role of nateglinide and repaglinide, derivatives of meglitinide, in the treatment of type 2 diabetes mellitus. Arch Med Sci 2013; 9: 936-43.

43. Scheen AJ. Pharmacokinetic interactions with thiazolidinediones. Clin Pharmacokinet 2007; 46: 1-12.

44. Kirchheiner J, Thomas S, Bauer S, Tomalik-Scharte D, Hering U, Doroshyenko $\mathrm{O}$, et al. Pharmacokinetics and pharmacodynamics of rosiglitazone in relation to CYP2C8 genotype. Clin PharmacolTher 2006; 80: 657-67.

45. Hemauer SJ, Patrikeeva SL, Nanovskaya TN, Hankins GDV, Ahmed MS. Role of human placental apical membrane transporters in the efflux of glyburide, rosiglitazone and metformin. Am J Obstet Gynecol 2010; 202: 383.e1-e7.

46. Scheen AJ. Pharmacokinetics of dipeptidylpeptidase-4 inhibitors. Diabetes Obes Metab 2010; 12: 648-58.

47. Maladkar M, Sankar S, Kamat K. Teneligliptin: heralding change in type 2 diabetes. J Diabetes Mellitus 2016; 6: 113-131.

48. Scheen AJ. Dipeptidylpeptidase-4 inhibitors (Gliptins). Focus on drug-drug interactions. Clin Pharmacokinet 2010; 49: 573-88.

49. Chu XY, Bleasby K, Yabut J, Cai X, Chan GH, Hafey MJ, et al. Transport of the dipeptidyl peptidase- 4 inhibitor sitagliptin by human organic anion transporter 3, organic anion transporting polypeptide $4 \mathrm{C} 1$, and multidrug resistance P-glycoprotein. $J$ Pharmacol ExpTher 2007; 321: 673-83.

50. Kalra S. Sodium glucose co-transporter-2 (SGLT-2) inhibitors: a review of their basic and clinical pharmacology. Diabetes Ther 2014; 5: 355-66.

51. Lamos EM, Younk LM, Davis SN. Canagliflozin, an inhibitor of sodium-glucose cotransporter 2, for the treatment of type 2 diabetes mellitus. Expert Opin Drug MetabToxicol 2013; 9: 763-75.

52. Scheen AJ. Pharmacokinetic and pharmacodynamic profile of empagliflozin, a sodium glucose co-transporter 2 inhibitor. Clin Pharmacokinet 2014; 23: 213-25. 
53. Kasichayanula S, Liu X, Lacreta F, Griffen SC, Boulton DW. Clinical pharmacokinetics and pharmacodynamics of dapagliflozin, a selective inhibitor of sodium-glucose co-transporter type 2. Clin Pharmacokinet 2014; 53: 17-27.

54. Devineni D, Curtin CR, Polidori D, Gutierrez MJ, Murphy J, Rusch $\mathrm{S}$, et al. Pharmacokinetics and pharmacodynamics of canagliflozin, a sodium glucose co-transporter 2 inhibitor, in subjects with type 2 diabetes mellitus. J Clin Pharmacol 2013; 53: 601-10.

55. Obermeier $M$, Yao $M$, Khanna $A$, et al. In vitro characterization and pharmacokinetics of dapagliflozin (BMS-512148), a potent sodium-glucose cotransporter type II inhibitor, in animals and humans. Drug Metab Dispos 2010; 38: 405-14.

56. Plosker GL. Canagliflozin: a review of its use in patients with type 2 diabetes mellitus. Drugs 2014; 74: 807-24.

57. Umehara KI, Iwatsubo T, Noguchi K, Usui T, Kamimura H. Effect of cationic drugs on the transporting activity of human and rat OCT/Oct 1-3 in vitro and implications for drug-drug interactions. Xenobiotica 2008; 38: 1203-18.

58. Bachmakov I, Glaeser H, Endress B, Mörl F, König J, Fromm MF. Interaction of beta-blockers with the renal uptake transporter OCT2. Diabetes Obes Metab 2009; 11: 1080-3.

59. Zolk O, Solbach TF, König J, Fromm MF. Structural determinants of inhibitor interaction with the human Organic Cation Transporter OCT2 (SLC22A2). Naunyn-Schmied Arch Pharmacol 2008; 379: 337-48.

60. Müller F, König J, Glaeser H, Schmidt I, Zolk O, Fromm MF, et al. Molecular mechanism of renal tubular secretion of the antimalarial drug chloroquine. Antimicrob Agents Chemother 2011; 55 : 3091-8.

61. Meyer zu Schwabedissen HE, Verstuyft C, Kroemer HK, Becquemont L, Kim RB. Human Multidrug and Toxin Extrusion 1 (MATE1/SLC47A1) transporter: Functional characterization, interaction with OCT2 (SLC22A2), and single nucleotide polymorphisms. Am J Physiol Renal Physiol 2010; 298: F997-F1005.

62. Umehara KI, Iwatsubo T, Noguchi K, Kamimura H. Comparison of the kinetic characteristics of inhibitory effects exerted by biguanides and $\mathrm{H} 2$-blockers on human and rat organic cation transporter-mediated transport: insight into the development of drug candidates. Xenobiotica 2007; 37: 618-34.

63. Wang ZJ,Yin OQ, Tomlinson B, Chow MS. OCT2 polymorphisms and in-vivo renal functional consequence: studies with metformin and cimetidine. Pharmacogenet Genomics 2008; 18: 637-45.

64. May M, Schindler C. Clinically and pharmacologically relevant interactions of antidiabetic drugs. Ther Adv Endocrinol Metab 2016; 7: 69-83.

65. MinematsuT, Giacomini KM. Interactions of tyrosine kinase inhibitors with organic cation transporters and multidrug and toxic compound extrusion proteins. Mol CancerTher 2011; 10: 531-9.

66. Zheng, HX, Huang Y, Frassetto LA, Benet LZ. Elucidating rifampin's inducing and inhibiting effects on glyburide pharmacokinetics and blood glucose in healthy volunteers: Unmasking the differential effects of enzyme induction and transporter inhibition for a drug and its primary metabolite. Clin PharmacolTher 2008; 85: 78-85.
67. Fuchikami H. Effects of herbal extracts on the function of human organic anion-transporting polypeptide OATP-B. Drug Metab Dispos 2006; 34: 577-82.

68. Lilja JJ, Niemi M, Fredrikson H. Effects of clarithromycin and grapefruit juice on the pharmacokinetics of glibenclamide. $\mathrm{Br} \mathrm{J}$ Clin Pharmacol 2007; 63: 732-40.

69. Grube M, Köck, K, Oswald S, Draber K, Meissner, K, Eckel L, et al. Organic anion transporting polypeptide 2B1 is a high-affinity transporter for atorvastatin and is expressed in the human heart. Clin PharmacolTher 2006; 80: 607-20.

70. Hirano M, Maeda K, Shitara Y, Sugiyama Y. Drug -drug interaction between pitavastatin and various drugs via OATP1B1. Drug Metab Dispos 2006; 34: 1229-36.

71. Gong IY, Kim RB. Impact of genetic variation in OATP transporters to drug disposition and response. Drug Metab Pharmacokinet 2013; 28: 4-18.

72. Gedeon C, Behravan, J, Koren G, Piquette-Miller M. Transport of glyburide by placental $A B C$ transporters: Implications in fetal drug exposure. Placenta 2006; 27: 1096-102.

73. Mita S. Inhibition of bile acid transport across $\mathrm{Na}+$ taurocholate cotransporting polypeptide (SLC10A1) and bile salt export pump (ABCB11)-coexpressing LLC-PK1 cells by cholestasis-inducing drugs. Drug Metab Dispos 2006; 34: 1575-81.

74. Kis E, loja E, Nagy T, Szente L, Heredi-Szabo K, Krajcsi P. Effect of membrane cholesterol on BSEP/Bsep activity: species specificity studies for substrates and inhibitors. Drug Metab Dispos 2009; 37: 1878-86.

75. Kalliokoski A, Backman JT. Effects of gemfibrozil and atorvastatin on the pharmacokinetics of repaglinide in relation to $\mathrm{SL}$ C01B1 polymorphism. Clin PharmacolTher 2008; 84: 488-96.

76. Niemi M. The cytochrome P4503A4 inhibitor clarithromycin increases the plasma concentrations and effects of repaglinide. Clin PharmacolTher 2001; 70: 58-65.

77. Nozawa T, Sugiura S, Nakajima M, Goto A, Yokoi T, Nezu J, et al. Involvement of organic anion transporting polypeptides in the transport of troglitazone sulfate: Implications for understanding troglitazone hepatotoxicity. Drug Metab Dispos 2004; 32: 291-4.

78. Gui C, Miao Y, Thompson L, Wahlgren B, Mock M, Stieger B, et al. Effect of pregnane $X$ receptor ligands on transport mediated by human OATP1B1 and OATP1B3. Eur J Pharmacol 2008; 584: 57-65.

79. Bachmakov I, Glaeser H, Fromm MF, König J. Interaction of oral antidiabetic drugs with hepatic uptake transporters: focus on organic anion transporting polypeptides and organic cation transporter 1. Diabetes 2008; 57: 1463-9.

80. Choi MK, Jin QR. Sitagliptin attenuates metformin-mediated AMPK phosphorylation through Inhibition of organic cation transporters. Xenobiotica 2010; 40: 817-25.

81. He YL, Ligueros-Saylan M, Sunkara G, Sabo R, Zhao C, Wang $Y$, et al. Vildagliptin, a novel dipeptidyl peptidase IV inhibitor, has no pharmacokinetic interactions with the antihypertensive agents amlodipine, valsartan, and ramipril in healthy subjects. $J$ Clin Pharmacol 2008; 48: 85-95. 